\title{
Descrições de Cargos
}

\author{
Tradução de RAIMundo XAVIER DE MENEZES
}

\begin{abstract}
O trabalho apresentado em seguida é uma tradução do Capítulo VII do Manual de Classificação de Cargos do Ministério da Marinha dos Estados Unidos da América. Refere-se êle à questão das descrições de cargos. um dos pontos mais delicados e significativos do processo de classificação de cargos pràticamente sempre omitido entre nós. Ao oferecermos esta tradução, convém chsmar a atenção do leitor para não confundir a descrição de cargo com a especificação de classe, coisas distintas, que atendem a finalidades diversas.
\end{abstract}

(Nota do Tradutor).

Descrições de cargos: conceituação - Uma descrição de cargo consiste na exposição escrita de fatos importantes para a administração e concernentes às atribuições, responsabilidades e relações organizacionais inerentes a um cargo. O conteúdo de cada cargo aparece em combinações tão variadas que sua descrição não pode integrar-se numa fórmula rígida, com itens predeterminados. Conseqüentemente, a parte principal da descrição do cargo é usualmente dactilografada numa fôlha de papel comum e anexada a modêlo próprio, que consiste, antes de tudo, numa capa, utilizada para fins de identificação e autenticação.

Porque se necessita de descrições de carǵo - As organizações são compostas de cargos, da mesma forma que as máquinas, de partes. Uma descrição de cargo é uma espécie de mapa de um setor de uma organização.

A classificação de cargos por si só já fornece motivo para justificar a necessidade das descrições de cargo, mas há outros fins a que estas se destinam. Por exemplo, se um supervisor ou técnico de administração está interessandose pela melhoria dos métodos de trabalho e de estrutura da organização, poderá precisar de informações mais detalhadas sôbre os cargos em causa do que as indicadas por seus títulos e graus. Há outros exemplos de utilização das descrições de cargo, como sejam: possibilitar ao técnico de treinamento uma compreensão melhor das tarefas para que os empregados devem ser treinados; servir ao técnico de orçamento quando necessita de informações pormenorizadas sôbre a organização, para fins orçamentários; auxiliar o encarregado da lotação a encontrar para o funcionário o cargo mais conveniente, entre aquêles grupados na mesma classificação; facilitar ao técnico de seleção a ponderação dos registros funcionais anteriores de um empregado; auxiliar o supervisor no esclarecimento dos empregados quanto às suas novas atribuições, e permitir clareza e uniformidade de entendimento, sempre que houver necessidade de duas ou mais pessoas consentirem no conceito de um cargo. 
Quando são necessárias as descrições de cargo - Sempre que um novo cargo é criado, impõe-se a elaboração de sua descrição. Por outro lado, é necessária nova descrição quando as atribuições, responsabilidades, ou relações organizacionais de determinado cargo se houverem alterado substancialmente. A simples substituição de um empregado por outro num cargo não requer nova descrição, salvo se, por fôrça da troca, o cargo houver sofrido alteração de conteúdo. Qualquer modificação no conteúdo ocupacional de um cargo deve prontamente determinar a revisão de sua descrição. Contudo, as descrições novas, de ordinário, não devem ser elaboradas antes de perfeitamente consolidadas as modificações. Compete a todo supervisor rever periòdicamente os cargos de seu setor, a fim de saber, em qualquer época, quais as descrições de cargo desatualizadas, evitando deixar que as mesmas se prolonguem, nesse estado, sem a devida retificação.

Quem deve elaborar as descrições de cargo - Não nos interessa aqui quem responde aos itens de identificação e autentificação comuns na fórmula de descrição de cargo, mas, sim, quem elabora a exposição descritiva a constar da mesma ou das fôlhas suplementares apensas.

E política do Ministério da Marinha que tôda descrição de cargo deva ser elaborada pela pessoa que melhor conheça o cargo. Em condições ordinárias, obtêm-se melhores classificações, com menor demora, quando os próprios empregados, empenhados na execução do trabalho, redigirem as descrições de cargo. Por êste motivo, o Ministério da Marinha vem adotando a prática geral de que as descrições sejam preparadas pelos próprios empregados. $\mathrm{O}$ objetivo dessa prática é a obtenção de melhores descrições de cargo. Em conformidade com essa orientação, a fim de guiar a quem deva elaborar as descrições de cargo, cumpre observar as seguintes regras:

1. Na maioria dos casos, o supervisor competente é responsável pela iniciativa da classificação. Em qualquer hipótese, cabe-lhe cuidar para que seja feita uma apresentação precisa dos fatos importantes. E seu dever, por. tanto, orientar a preparação de cada descrição de cargo.

2. Caso as atribuições de um cargo estejam sendo executadas regularmente por um empregado, compete-lhe ordinàriamente a descrição do mesmo. Sempre que necessário, o empregado deve ser orientado pelo supervisor, quanto ao exame do cargo e à maneira de descrevê-lo, antes de ser dada forma definitiva à descrição.

3. Incumbe ao supervisor competente fazer as descrições quando:

a) O trabalho inerente ao cargo não estiver, de modo regular, sendo executado por uma pessoa, já porque as atribuições do cargo não tenham ainda sido conferidas a um empregado, já pela ausência do ocupante por longo período;

b) As atribuições do cargo estiverem sendo executadas por empregado novo, ainda não familiarizado com as mesmas, e haja boas razões contra n adiamento da preparação da descrição para época mais oportuna;

c) As atribuições do cargo estiverem sofrendo, ou a ponto de sofrer, alterações substanciais e houver razões plausíveis contra o adiamento da preparação da descrição para quando o empregado se tornar suficientemente familiarizado com suas tarefas, na forma modificada. 
4. Os supervisores, ou outros funcionários para isso autorizados, devem assistir o empregado na preparação de sua descrição, quando tal assistência fôr reclamada. Não convém, todavia, que êsse auxílio elimine a participação ativa do empregado na elaboração da descrição. Constitui violação da política do Ministério da Marinha o fato de um técnico em classificação retirar dos empregados e supervisores a responsabilidade pela apresentação dos fatos relativos aos cargos a classificar.

A descrição, quando preparada por um empregado, precisa ser revista pelo supervisor, com o fim de assegurar-1he rigor e propriedade. A melhor época para isto é no momento em que a descrição ainda esteja em rascunho. O supervisor deve, em primeiro lugar, certificar-se de que esteja clara e suficientemente completa. Em seguida, deve verificar se há necessidade de reforçar ou abrandar alguns pontos, ou quais os que não foram suficientemente acentuados ou foram exagerados. Se o empregado possuir um conceito errôneo da extensão de seu trabalho, do seu grau de responsabilidade, ou das relações do seu com os outros cargos, compete ao supervisor corrigir tais incompreensões. Cumpre envidar todos os esforços para se conseguir um acôrdo entre o empregado e o supervisor quanto à maneira de descrever o cargo. Caso não encontrem um denominador comum, convém que ambos registrem seus pontos de vista e os façam constar junto ao modêlo próprio. Dêsse modo, reconhecem-se o direito e a responsabilidade de cada empregado em descrever suas atividades tais como as entenda, assegurando-se, outrossim, a atenção devida ao interêsse honesto do empregado pela classificação de seu cargo.

Se a descrição feita pelo empregado revelar que as atribuições executadas não se harmonizam com o plano de trabalho adotado, cabe ao supervisor alterar e ajustar a distribuição das tarefas. As classificações se baseiam nas descrições de cargo; assim sendo, estas devem ser atualizadas, sempre que haja qualquer alteração.

Que informações as descrições de cargo devem conter - Raramente, ou talvez nunca, uma descrição de qualquer coisa exige referências completas a todos os detalhes dos diversos aspectos do objeto. A descrição melhor é aquela que dá uma boa idéia do conjunto, concentrando-se, porém, nos aspectos mais importantes.

Muitas das particularidades de um cargo podem ser insignificantes para fins de sua classificação. Por outro lado, todo cargo tem uma série de pontos de importância capital. Portanto, os elaboradores de descrições de cargo terão sempre que responder a esta questão básica: Quais os aspectos importantes?

Há alguns princípios que podem servir de guia na seleção dos fatos. Sua discussão, porém, está prêsa à questão de como elaborar as descrições, que è tratada no capítulo VIII. Não obstante é aconselhável adiantar aqui alguns esclarecimentos.

O escopo das descrições de cargo é atender às necessidades de quem as vai usar. Já discutimos a utilidade das descrições de cargo nas várias fases da administração, como sejam, a análise de organização e métodos, o treinamento e a lotação de pessoal. Dêsse modo, cumpre que satisfaçam a uma multiplicidade de aspectos. Já ficou constatado que as descrições, quando elaboradas de modo adequado para responder às exigências da classificação de cargos. se prestam, também, eficientemente, às demais finalidades. 
Para efeito de classificação, as descrições devem conter as informações necessárias à determinação da natureza do cargo (característica profissional) e do respectivo nível de dificuldades e responsabilidades (grau). As características profissionais podem usualmente ser identificadas através de uma apreciação global do cargo, ao passo que a determinação dos graus está condicionada ao exame de detalhes. As diferenças entre um Estenógrafo grau 3 e outro grau 4, ou entre um Físico grau 11 e outro grau 12, não são grandes. A razão de tais diferenças de classificação comumente só podem ser encontradas nos pormenores de peculiaridades relativas à dificuldade e responsabilidade inerentes ap trabalho. Conseguintemente, as descrições de cargo devem relacionar informações detalhadas que sirvam para esclarecer o nível relativo de dificuldade e responsabilidade do trabalho, e, para evitar confusão, devem omitir quanđo não contribua para êsse esclarecimento. Neste particular, a determinação do que é relevante, ou irrelevante, será melhor levada a efeito através do que se entende por fatôres de classificação.

Antes de entrarmos na discussão dos chamados fatôres de classificação, devemos dispensar atenção a alguns pontos específicos pertinentes ao conteúdo das descrições de cargo, mas não diretamente relacionados com aquêles fatôres. Eis algumas sugestões de como se deve proceder com relação a certas questões peculiares às descrições de cargo.

Funcionamento e estrutura organizacional - Não aprecie aspectos gerais relativos à estrutura e funcionamento da organização, onde se encontra seu cargo. Cabe ao classificador a obtenção dessas informações em outras fontes. Contudo, esclareça onde exatamente figura seu cargo, do ponto de vista organizacional, e quais as funções e objetivos especificamente inerentes ao mesmo. Caso as atribuições de seu cargo estejam em relação de dependência com as de outro, explique essa circunstância.

Processos, sistemas de operação, métodos, fluxo do trabalho, formulários etc. - Não discuta aspectos gerais dêsses assuntos. O classificador os conseguirá alhures. Esclareça, porém, o ponto em que seu cargo se entrosa com essas práticas e sistemas de execução. Explique de onde vem seu trabalho, em que estágio de execução êle o atinge, qual a contribuição que êle presta à operação, e para onde se encaminha o resultado do trabalho. Suponha que o classificador compreende a configuração e as finalidades de todos os formulários geralmente em uso, mas explique o que the importa fazer se vier a trabalhar com êles.

Programas de trabalho, volume e produção etc. - Parta do princípio de que o classificador está a par do programa de trabalho de sua seção e possui dados sôbre o volume de produção etc., mas explique quais os projetos em que estiver trabalhando, com que parcela concorre seu cargo para o esfôrço de produção da seção, etc.

Ciclos de trabalho, período de tempo necessário - Em princípio, as descriçôes de cargo devem abranger atividades correntes. Contudo, há muitos cargos com tarefas não executadas, na sua totalidade, no mesmo dia, na mes. ma semana, ou até no mesmo mês. Alguns cargos são uma mistura de atribuições diárias, periódicas e ocasionais. Outros ligam-se a projetos de natureza diversa, sendo que, com a conclusão de um, o empregado passa imediata. 
mente a empenhar-se no seguinte. Logo, nestes casos, uma descrição que se cinja às atividades de um dia, de uma semana, ou só um mês não fornecerá idéia completa e reál do cargo. Conseqüentemente, é claro que para cada cargo deve haver um período razoável, durante o qual suas atribuições se estendem. Tal período não pode ser expresso em têrmos de limites precisos de tempo, salvo, talvez, no caso de cargos, cujas tarefas ocorrem em ciclos uniformes ou seqüências repetitivas determinadas pela prática de execução. $\mathrm{Na}$ seleção dêsses períodos deve-se dispensar atenção tanto ao passado como ao futuro.

As atribuições anteriores só devem constar da descrição se se presumir que elas, ou outras semelhantes, vão repetir-se dentro de um determinado período e em consonância com as regras expostas abaixo para a inclusão de tarefas futuras.

$\mathrm{Na}$ descrição antecipada de atribuições futuras, convém atender às seguintes limitações:

1. Não deve ser descrita nenhuma tarefa que ainda não possa ser definitivamente concebida, quanto à amplitude e à maneira de execução.

2. Não deve ser descrito nenhum trabalho, com relação ao qual não haja certeza a que cargo será atribuído.

3. Não deve ser descrita nenhuma atribuição que, pela antecipação de futuro tão remoto, possa violar o princípio de salário corrente para trabalho corrente.

4. Não deve ser descrito nenhum trabalho que só possa ocorrer em caso de mobilização ou outra circunstância de fôrça maior. O Ministério da Marinha não está autorizado a retribuir o pessoal civil pela posse de capacidades cuja aplicação tenha caráter aleatório.

No caso de empregados que trabalham em certos projetos, tais como engenheiros e cientistas pesquisadores, nenhum projeto em particular ou grupo de projetos deve, ordinàriamente, servir de base única para a descrição do cargo Se não fôr observada essa cautela, a descrição pode, dentro de pouco tempo, tornar-se obsoleta, em virtude da mudança do empregado de um para outro projeto. A melhor providência, em casos dessa espécie, é elucidar os objetivos do cargo e a natureza da área funcional dentro da qual êle vai sempre atuar e funcionar. A participação do cargo em projetos específicos, como fonte de informações disponíveis, deve ser tomada como exemplo de atribuições do cargo e não como base única de sua existência.

Voltemos agora à questão da importância de informações, nas descrições de cargo, com relação ao que chamamos fatôres de classificação.

Freqüentemente faz-se referência à exigência de ponderação dos cargos na base de suas "dificuldades" e "responsabilidades" relativas. Estes são têrmos gerais habitualmente usados para indicar a variedade de elementos mais característicos dos cargos. Para possibilitar uma análise e apreciação mais precisas, devemos raciocinar em têrmos de elementos específicos (ou fatôres), os quais, pelo seu grau de participação ou de ausência, tornam um cargo mais, ou menos difícil e importante que outro. Os fatôres geralmente reconhecidos na classificação dos cargos federais são os constantes do modêlo elaborado pela Comissão do Serviço Civil (Civil Service Commission), a fim de orientar 
a descrição dos cargos. São êles periòdicamente atualizados e diferem um pouco dos que estão em uso no Ministério da Marinha. Tais variações são de somenos importância, uma vez que a área abrangida coletivamente pelos vários agrupamentos e definições de fatôres é, em substância, a mesma. Em virtude dessas variações, a sistematização dos fatôres que figura abaixo pode afastar-se do observado pelo leitor .em outras instruções mais específicas, tendentes a orientar a preparação da descrição do cargo. Caso tal se verifique, cumpre que o empregado siga as instruções mais específicas. $\mathrm{O}$ único propósito desta exposição é elucidar melhor a natureza das informações que as descrições de cargo devem conter, e não prescrever a forma de agrupamento das referidas informações.

Enumeram-se, em seguida, os fatôres sôbre os quais convém fornecer informações:

Natureza e fins do trabalho - As informações prestadas sob êste títulc servem a dois objetivos:

1. Permitem identificar o cargo esclarecendo sua posição e objetivo dentro da organização.

2. Permitem determinar o grau de condicionamento de um cargo pelas limitações, naturais ou de organização, intrínsecas ao próprio trabalho. Constituem o grau de contrôle - deliberado e planejado por autoridade superior - dentro de cujo âmbito o cargo terá que operar; e por outro lado, também consistem na amplitude específica ou nas limitações naturais ao trabalho. Por exemplo, um cargo pode consistir em tarefas de qualquer espécie em seu fichário de múltiplas finalidades; ou pode cingir-se à separação de material para tão sòmente um segmento de um arquivo especializado. Como outro exemplo, pode admitir-se que um cargo abranja aspectos diversos de desenho técnico de engenharia, ou poderá estar limitado a detalhes específicos dêsse gênero de trabalho.

Objetivo e efeito do trabalho - Êste fator indica a natureza e extensão da responsabilidade de um cargo. Não se inclui aqui a responsabilidade administrativa pela direção e coordenação do trabalho de outrem.

A responsabilidade geral de um cargo se reflete, primeiramente, no grau de sua contribuição para a consecução dos objetivos da unidade ou do serviço de que faz parte, e, em segundo lugar, no grau de dependência em que o trabalho de outros cargos se coloca relativamente ao funcionamento eficaz dêsse cargo que se procura descrever.

Pode existir responsabilidade específica na forma de prestação de contas, em relação a assuntos, tais como:

1. Processos, métodos, planos de organização, política administrativa etc.

2. Contrôle de dinheiro, trabalho, material, ou equipamento.

3. Desenvolvimento e manutenção de registros.

T'em-se outra indicação acêrca da responsabilidade quando se considera a importância que assume a exatidão na realização do trabalho afeto ao cargo. Isto se percebe melhor com a avaliação das conseqüências de erros, considerando-se:

1. Os efeitos não fàcilmente corrigiveis.

2. O custo das correções a serem feitas. 
Outro ponto que também cumpre levar em conta diz respeito à relativa dificuldade ou facilidade com que podem os erros ser evitados.

Supervisão e orientação recebida - Esste fator indica até que ponto um cargo é controlado ou orientado:

1. Supervisão de cargo ou cargos superiores. Os principais aspectos a considerar aqui são a medida em que a autoridade superior estabelece quando e como o trabalho deve ser executado; de que modo é orientada a execução, e qual a natureza e propósito da revisão final do trabalho.

2. O gênero de atribuições recebidas e o número das mesmas em que se deve atentar simultâneamente. Por exemplo, pode caber a um cargo, em atividades concomitantes, a realização de uma tarefa bem definida ou a de vários encargos de natureza geral e fronteiras vagas.

3. A extensão e natureza das instruções, da orientação e assistência dispensadas pelos superiores quando da distribuição do trabalho ou durante sua execução.

4. Métodos de execução, processos e sistemas; leis disciplinadoras, regulamentos, diretrizes e princípios; precedentes aplicáveis; práticas estabelecidas; rotinas aceitas relativas a uma profissão ou emprêgo; etc. Os aspectos importantes consistem, neste caso, em primeiro lugar, na medida em que tais instruções existem; em segundo lugar, em sua fôrça condicionadora; em terceiro lugar, no grau que sua interpretação exige do ocupante do cargo.

5. Orientação e auxílio recebidos de outra pessoa além do superior.

Requisitos mentais - Este fator deve indicar o grau em que o exercício do cargo requer:

1. Iniciativa, ou seja, capacidade mental para perceber e realizar o necessário, independentemente de instruções específicas.

2. Originalidade de concepção, poder criador ou inventivo - Este fator pressupõe a criação de maneiras novas de execução, a utilização incomum de idéias e métodos existentes, a incumbência de solucionar problemas não ainda equacionados, ou a análise de pesquisas, propostas e recomendações de terceiros, relacionados com êsses trabalhos.

3. Discernimento, ou a escolha entre duas alternativas. Neste caso pode estar compreendida a autoridade para decidir a responsabilidade de escolha entre várias formas de ação, ou a formulação de propostas quanto às decisões oficiais ou encaminhamento de providências.

4. Qualquer outro requisito mental incomum, tais como capacidade para apreender e reter um extenso número de coisas ou um complexo conjunto de fatos ou informações.

Contatos pessoais no trabalho - Este fator objetiva indicar a natureza e o grau de contatos pessoais exigidos pelo exercício de um cargo. Nêle não se compreendem as relações ordinárias entre supervisores e empregados subordinados, nem tão pouco entre os colegas de trabalho numa mesma unidade da organização.

A qualidade dos contatos é mais importante que a quantidade. A mera existência e freqüência dos contatos, se bem que importantes, não se aproxi. 
mam de seus propósitos e da dificuldade de sua efetivação. Por exemplo, um empregado informante pode gastar quase todo seu tempo dando resposta a perguntas orais. Contudo, se as informações necessárias se relacionarem com fatos concretos e se cada pergunta comportar uma resposta óbvia, então apenas uma parcela mínima dêste fator está presente. Por outro lado, um técnico de administração pode despender um décimo de seu expediente em contatos pessoais com autoridades executivas e legislativas para efeito de explicar, defender e conseguir seja aprovado o programa de administração de uma repartição. Vê-se, destarte, que o aspecto qualitativo do fator é tão grande, que se deve, ainda assim, não obstante a escassez dos contatos, admitir a presença do fator em grau relativamente alto.

A posição das pessoas compreendidas nos contatos não influi, necessàriamente, na maior ou menor importância do fator. Mesmo que alguns empregados tratem, com freqüência, pessoalmente, com altos funcionários, pode ocorrer que seja apenas para receber ou fornecer informações simples e definidas.

As respostas dadas às seguintes perguntas fornecem habitualmente informaçõès completas sôbre êste fator:

1. Com quem estabelece cortatos por fôrça do exercício do cargo?

2. Com que freqüência ocorrem êsses contatos?

3. Com que objetivo? (dar, receber ou trocar informações; para preparar planos ou programas; para obter aprovação de idéias, planos, políticas etc.; para participar de ações conjuntas). Dê exemplos.

4. Quais as condições existentes, que tornam fácil ou difícil a efetivação dos objetivos dêsses contatos?

Conhecimentos, competência e capacidades - Êste fator indica a espécie e grau de competência, conhecimentos e capacidades exigidos para o exercício de um cargo. Podem nêle estar compreendidos: destreza manual, conhecimentos profissionais, atitudes específicas etc. Não se devem incluir conhecimentos, competência e capacidades apenas desejáveis ou então as que um determinado ocupante possua, mas que dêle se não exijam para o exercício do cargo. Os requisitos não devem ser expressos em têrmos de educação formal ou experiência de trabalho. Convém pensar mais em têrmos do que é exigido e não de como os conhecimentos, competência e capacidades são obtidos.

Responsabilidade por trabalho de outrem - Este fator na realidade inclui vários elementos que deviam ser identificados separadamente, mas que seriam de apreciação rigorosa difícil, caso tentássemos isolá-los completamente. Em sentido lato, êste fator consiste de dois elementos. Um dêles está relacionado com a natureza do contrôle sôbre cargos inferiores; o outro, com a magnitude de tal contrôle.

Há muitas espécies de cargos supervisores: estendem-se da simples chefia de turma aos de direção máxima. Possuem êste fator em pequeno grau os cargos cuja supervisão seja de natureza simples e rotineira, tal como distribuir o trabalho e atender a que sua execução siga o costumeiro padrão de processamento estabelecido. Em contraste, os cargos com graus elevados dêste fator podem conter responsabilidades complexas, tais como planejamento de opera- 
ções de trabalho, seleção do número e espécie de pessoal, distribuição de pessoal por projetos empreendidos, incumbência de tarefas, aumento ou diminuição do quadro de pessoal, segundo as necessidades, e tratamento dos problemas de disciplina, bem estar e moral dos empregados.

O índice mais concreto da maǵnitude do contrôle supervisor é o número de cargos supervisionados. O elemento essencial aqui é o grau de dificuldade intrínseco à coordenação dos esforços do grupo. Se bem que tal dificuldade possa não ser substancialmente influenciada pelas variações do número dos supervisionados sob os cuidados de um chefe, é igualmente claro que há diferença entre um supervisor que controla a atividade de cem empregados e outro com apenas cinco subordinados. O número dêstes, portanto, constitui fato relevante a ser registrado na avaliação.

Os fatôres acima discutidos abrangem tudo que é ordinàriamente importante na avaliação de um cargo.

Sua apreciação assegura que, sem se considerar o caso particular de um supervisor, de um subordinado, de um técnico ou especialista em qualquer grau, sempre o cargo poderá ser devidamente avaliado na base dos fatôres contidos nas suas atribuições e responsabilidades. Se uma descrição expõe com expressivos detalhes em que consistem as tarefas de um cargo e, ao mesmo tempo, expõe com clareza tais incumbências em função dos fatôres acima examinados, ela será de importância e adequada aos fins de classificação.

A extensão das descrições de cargo - A extensão de uma descrição de cargo é mais ou menos proporcional à de uma carta. Deve ser suficientemente longa para atingir seus objetivos e suficientemente concisa para evitar o desperdício de tempo dos que vão com ela lidar.

O registro de um grupo de atribuições deve regular em espaço com os demais. Raramente uma só página será bastante, mas é muito pouco provável que se necessite de dez páginas.

Se nos propomos relatar o que deve ser conhecido, a fim de possibilitar compreensão clara de um cargo à luz dos fatôres acima discutidos, convém que nos atenhamos aos fatos, evitemos minúcias, nos cifremos aos aspectos principais do trabalho; não incidamos em repetições e resistamos a qualquer inclinação para empregar argumentos ou ornamentações enfáticas, antes destinadas a exaltar o cargo do que a elucidar-lhe a natureza. Se assim procedermos podemos estar certos de que a descrição se circunscreveu às proporções devidas. 